\title{
Pelaksanaan Magang Program Pengembangan Kewirausahaan di CV Bintang Lima Mahardikka
}

\author{
A. R Nurhikmawati ${ }^{*}$, D. S Hariyani ${ }^{2}$, Pujiati ${ }^{3}$, W. L Yuhanna ${ }^{4}$, Davi Apriandi ${ }^{5}$, Tomas \\ Dewantoro $^{6}$
}

1,2,3,4,5,6 Pengembangan Kewirausahaan Kampus (PPK), Universitas PGRI Madiun

\section{A R T I C L E I N F O}

Article history:

Received 20 August 2018

Received in revised form

15 September 2018

Accepted 24 Oktober 2018

Available online 27

November 2018

Kata Kunci:

kewirausahaan, desain,

manajemen

Keywords:

Design, Entrepreneurship,

Management

\begin{abstract}
A B S T R A K
Pelaksanaan magang yang dilaksanakan di CV. Bintang Lima Mahardikka, Metode dasar yang digunakan dalam praktik magang ini adalah Observasi, Studi Lapangan, Wawancara dan Studi Pustaka. Adapun yang melatar belakangi lokasi magang dilakukan di CV. Bintang Lima Mahardikka adalah kesesuaian antara perusahaan tersebut dengan usaha mahasiswa yang akan dikembangkan dalam Program Pengembangan Kewirausahaan (PPK). Selain itu, perusahaan tersebut telah berhasil mengadakan berbagai macam event besar di wilayah Madiun Kota yang merupakan lokasi pengembangan usaha mahasiswa. CV. Bintang Lima Mahardikka memiliki manajemen yang sangat baik. Perusahaan tersebut membawahi dua perusahaan lainnya: SatuAtap yang bergerak dalam persewaan peralatan event serta Event Organizer (EO), dan A1 Media yang menangani periklanan seperti percetakan sekaligus pemasangan baliho dan PNTV. Dari praktik magang yang dilakukan selama 33 hari, mahasiswa bersama timnya berhasil membuat beberapa desain untuk klien CV. Bintang Lima Mahardikka
\end{abstract} dengan panduan divisi desain perusahaan tersebut. Selain itu, mahasiswa juga ambil bagian dalam pengadaan event Bluder Cokro Fest 2018 dan Madiun Motor Fest 2018. Hingga kegiatan magang berakhir, semua berjalan baik dan lancar dengan kerjasama tim yang baik antara mahasiswa magang dengan tim CV. Bintang Lima Mahardikka.

\section{A B S T R A C T}

The background of the apprentice location done in CV. Bintang Lima Mahardikka is the suitability of the related company to the student business that is under supervision of Program Pengembangan Kewirausahaan or Entrepreneurship Development Program from DIKTI. In addition, that company has successfully held a large variety of events in Kota Madiun Kota, which is the location of student business, and in Jawa Timur as well. CV. Bintang Lima Mahardikka has excellent management and oversees two other companies: SatuAtap which engages in event equipment rental and event organizer, and A1 Media which handles advertising such as printing as well as billboard and PNTV installation. The basic methods used in this internship are observation, field study, interview and library study. From 33-day internship process, the students managed to create several designs for company's clients with the guidance of the design division. Furthermore, students also took part in the launching event Bluder Cokro Fest 2018 and Madiun Motor Fest 2018. It can be concluded that in the end of the internship, the process went well in an efficient way, the students learned a lot about production from the start until how to market the product, and there was a good teamwork between students and the company's team.

\footnotetext{
Corresponding author.

E-mail addresses: agitarnurhikmawati@unipma.ac.id (A. R Nurhikmawati)
} 


\section{Pendahuluan}

Magang menjadi salah satu kegiatan wajib dalam Program Pengembangan Kewirausahaan (PPK) yang merupakan program kerja sama antara Universitas PGRI Madiun dengan instansi/perusahaan untuk meningkatkan pemahaman dan pengalaman secara langsung di dunia kerja. Di dalam dunia kerja di era yang semakin canggih teknologi dan ilmu pengetahuannya yang berkembang sangat pesat mempengaruhi, standar perusahaan dalam perekrutan tenaga kerja. Dengan demikian untuk membentuk SDM (Sumber Daya Manusia) yang mampu bersaing di Dunia Industri/Dunia Usaha (DU/DI) maka magang merupakan kegiatan yang tepat bagi mahasiswa untuk mengembangkan kemampuan dan sebagai tempat untuk menyalurkan ide dan mendapat wawasan baru sehingga dapat mengembangkan pola pikir. Dengan Pola pikir yang berkembang diharapkan mahasiswa memiliki rasa tanggung jawab terhadap apa yang ditugaskan untuk mahasiswa. Sehingga terbentuk tenaga kerja yang bermutu dan berkualitas, baik secara profesional, personal, maupun sosial.

Adapun tujuan kegiatan magang yang dilaksanakan adalah untuk mengembangkan kemampuan dan profesional, meningkatkan jaringan kerja sama, memperluas wawasan dan ilmu pengetahuan, meningkatkan kemampuan mahasiswa dalam bidangnya, mempersiapkan ilmu pengetahuan mental dan etika bekerja serta menyesuaikan diri dalam menghadapi dunia kerja sesungguhnya, mengetahui pola kerja dan manajemen suatu perusahaan.

Kegiatan praktik magang dilaksanakan pada 10 April 2018 sampai 12 Mei 2018. Mahasiswa magang diharuskan masuk minimal selama 3 jam dalam satu hari atau memenuhi jam kerja sebanyak 60 jam pada magang yang dilaksanakan. Tempat magang (praktik kerja lapangan) bertempat di CV. Bintang Lima Mahardikka atau lebih dikenal dengan "Bintang 5 Production" berlokasi di Jalan Pringgondani No.1, Madiun.

Dasar Teori Desain Grafis

Menurut Jessica Helfand(2016) desain grafis adalah kombinasi kompleks kata-kata dan gambar, angka-angka dan grafik, foto-foto dan ilustrasi yang membutuhkan pemikiran khusus dari seorang individu yang bisa menggabungkan elemen-elemen ini, sedangkan menurut Suyanto, desain grafis merupakan aplikasi dari keterampilan seni dan komunikasi yang digunakan untuk kebutuhan bisnis dan industri. Pengaplikasian tersebut bisa berupa pengiklanan yang menciptakan identitas untuk suatu produk, perusahaan ataupun event / kegiatan secara visual.

Elemen-elemen dalam Desain Grafis

Dalam buku Desain Komunikasi Visual Teori dan Aplikasi yang dikemukakan oleh Rahmat Supriyono (2010) Ada beberapa elemen visual yang perlu diketahui dan ditata dalam penataannya sehingga dapat menghasilkan komposisi desain yang harmonis, menarik, dan komunikatif. Elemenelemen dasar grafis tersebut terdiri dari:

Garis

Garis adalah tanda yang dibuat oleh alat untuk menggambar melewati permukaan. Garis dapat juga merupakan potongan di permukaan yang keras yang biasa disebut grafis. Garis juga dapat dikatakan sebagai suatu himpunan titik-titik yang anggotanya terdiri dari lebih dari satu titik. Garis juga dapat didefinisikan sebagai titik-titik yang bergerak. Selain itu, garis juga disebut sebagai jalur terbuka. Wujud garis sangat bervariasi, tipe garis merujuk pada gerakan garis awal hingga akhir. Garis lurus mempunyai kesan kaku dan formal. Garis lengkung memberi kesan lembut dan luwes. Garis zig-zag terkesan keras dan dinamis. Garis tak beraturan mempunyai kesan fleksibel dan tidak formal. Tipe garis yang merujuk pada arah garis menggambarkan hubungan antar garis terhadap halaman. Garis-garis horizontal memiliki kesan pasif, tenang dan damai. Sedangkan garis vertikal memiliki kesan stabil, gagah, dan elegan. Sementara garis diagonal lebih terlihat aktif, dinamis, bergerak dan menarik perhatian. Selain penjelasan di atas, garis dapat diolah lebih kreatif lagi sebagai elemen desain yang artistik. Garis dapat dibuat putusputus, gradasi, tabal-tipis, dan variasi lainnya sesuai dengan kebutuhannya.

Bidang

Elemen grafis yang kedua adalah bidang. Bidang adalah segala bentuk yang memiliki ukuran tinggi dan lebar. Bidang dapat berupa bentuk-bentuk geometris (lingkaran, segitiga, segi empat, elips, setengah lingkaran, dan sebagainya) dan bentuk-bentuk yang tidak beraturan. Bidang geometris memiliki kesan formal. Sebaliknya, bidang-bidang yang tidak geometris memiliki kesan tidak formal, santai dan dinamis. Pengertian bidang dalam desain grafis tidak sebatas itu saja. Area kosong di antara elemen-elemen visual dan space yang mengelilingi, dapat disebut sebagai bidang. Bidang kosong bahkan dapat dianggap sebagai elemen desain. 


\section{Warna}

Warna merupakan elemen grafik yang sangat kuat dan provoaktif. Secara spontan orang terkesan jika melihat warna, karena warna berpengaruh kuat dan dapat menjadi pendorong, sehingga dapat menarik perhatian. Dalam penggunaan warna perlu diperhatikan komposisinya agar tidak merusak citra. Warna-warna soft mempunyai kesan lembut, tenang dan romantik. Warna-warna kuat dan kontras dapat memberi kesan dinamis, cenderung meriah. Dalam seni rupa, warna dapat dilihat dari tiga dimensi, yaitu: (1) Hue - pembagian warna berdasarkan nama-nama warna, seperti merah, kuning, hijau dan seterusnya, (2) Value - terang gelapnya warna, (3). Intensity - tingkat kejernihan warna. Berdasarkan dimensi Hue, warna dibagi menjadi tiga golongan, yaitu warna primer, warna sekunder dan warna tersier. Secara visual warna dapat dibagi menjadi dua golongan, yaitu warna dingin dan warna panas. Warna-warna dingin seperti hijau, biru, dan ungu dapat memiliki karakteristik sejuk, pasif, terang, statis, kalem. Warna - warna ini melambangkan kesucian dan damai. Sebaliknya, warna-warna panas seperti merah, oranye, dan kuning memiliki kesan hangat, dinamis, aktif dan warna terkuat dan paling mengundang perhatian. Dimensi warna yang kedua adalah Value, yaitu gelap-terangnya warna. Semua warna dapat dikurangi atau diperlemah kekuatannya dengan cara dibuat lebih terang atau dibuat lebih gelap. Selain Hue dan Value, warna dapat dilihat dari aspek Intensity, yaitu tingkat kemurnian atau kejernihan warna. Suatu warna dikatakan memiliki intensitas penuh saat tidak dicampur dengan warna lain. Intensitas warna dapat berkurang menjadi lebih redup dan netral saat tercampur dengan sedikit warna lain.

Gelap-terang

Kontras value bersifat relatif, sangat dipengaruhi oleh background dan elemen-elemen lain di sekitarnya. Dalam desain komunikasi visual dapat digunakan untuk menonjolkan pesan atau informasi dan memberikan nilai ekspresi. Penggunaan warna-warna yang kurang kontras cenderung terkesan kalem, damai, statis, serta tenang. Sebaliknya, penggunaan warna-warna kontras dengan ekstrem, menghasilkan visual yang enerjik, ceria, dinamis dan penuh gairah. Berdasarkan nilai gelap dan terangnya, warna dibagi menjadi beberapa tingkatan yaitu mulai dari warna paling terang, sangat terang, terang, sedang dan yang paling terang. Warna-warna terang akan sangat mudah terbaca jika ditempatkan pada background gelap, dan sebaliknya warna gelap akan lebih terbaca bila ditempatkan pada background terang.

\section{Tekstur}

Tekstur adalah kualitas permukaan atau kualitas papan atau pun kualitas kertas. Di dalam seni, tekstur dikategorikan menjadi dua bagian yaitu tekstur tactile dan tekstur visual. Tekstur tactile adalah bersifat nyata, sehingga teksturnya dapat dirasakan permukaannya. Sedangkan tekstur visual adalah ilusi, tekstur tersebut memberikan impresi yang sederhana dari tekstur yang nyata. Tekstur tactile dapat diciptakan dengan berbagai cara, yaitu dengan cara memotong dan mengelem pada tekstur. Selain itu, tekstur juga melakukan embrossing (permukaan yang muncul) dengan mengimpresi tekstur dalam relief. Sedangkan tekstur visual diciptakan menggunakan garis, dan warna

Ukuran

Besar-kecilnya elemen visual perlu diperhitungkan secara tepat sehingga desain komunikasi visual memiliki nilai kemudahan baca yang tinggi. Dengan membuat skala prioritas merupakan langkah awal untuk mempermudah penyusunan elemen-elemen desain. Besar-kecilnya ukuran huruf untuk judul, sub judul, dan teks perlu diperhitungkan. Demikian pula dengan foto, perbedaan ukuran yang proporsional akan membantu pembaca dalam memilih informasi yang perlu didahulukan. Jadi perlu ditentukan hierarki visual, yaitu mulai dari yang sangat penting, penting, dan kurang penting.

Prinsip Desain Grafis

(a) Keseimbangan (Balance), Keseimbangan merupakan sebuah stabilitas yang dapat tercipta melalui tampilan berat pada visual dari titik pusat yang terbagi secara merata pada setiap sisinya. Sebuah karya memiliki keseimbangan agar nyaman dipandang dan mudah dipahami. Setiap elemen desain memiliki kekuatan dan berat yang terpancar secara visual. Tampilan berat pada setiap elemen desain secara visual tergantung pada beberapa faktor seperti ukuran, bentuk, warna dan tekstur yang dimiliki oleh masingmasing elemen. Apabila elemen desain diletakkan secara teratur, maka akan menciptakan sebuah komposisi yang terlihat seimbang secara keseluruhan. Keseimbangan tidak dapat diukur tapi dapat dirasakan, yaitu semua bagian sebuah karya tidak ada yang saking membebani.

Dalam sebuah keseimbangan, terdapat 2 pendekatan dasar yaitu keseimbangan simetri dan asimetris. Keseimbangan simetri memiliki tampilan berat secara visual yang seimbang dan stabil dari semua sisi (atas, bawah, kanan, dan kiri) dengan komposisi yang disusun dengan teratur, sedangkan keseimbangan asimetris memiliki tampilan berat yang stabil secara visual walaupun peletakan pada komposisi tidak tersusun secara teratur (Landa dkk., 2007), (b)Tekanan (Emphasis) Tekanan dapat dicapai dengan beberapa cara yaitu tekanan melalui tata letak, ukuran, kontras, arah, dan struktur diagram. Dalam menciptakan tekanan, seorang desainer perlu menampilkan konten yang disusun secara 
logis serta mengontrol bagaimana cara informasi atau pesan dapat tersampaikan (Landa, 2011), (c)Irama (Rhythm) dengan membuat proses pengulangan (repetisi) pada berbagai macam elemen desain, maka akan tercipta pola dan irama. Irama adalah pengulangan gerak yang teratur dan terus menerus. Salah satu prinsip irama adalah hubungan pengulangan dan bentuk bentuk unsur unsur rupa. Selain itu, Irama mampu menciptakan sebuah gambar atau desain yang menarik serta mampu menyampaikan pesan atau informasi melalui cara yang tidak terduga sebelumnya (Landa, 2007). (d)Kesatuan (Unity) dalam desain dibutuhkan adanya kesatuan untuk menciptakan sebuah struktur komposisi dan perpaduan yang teratur antara satu elemen ke elemen desain lainnya. Kesatuan merupakan salah satu prinsip dasar desain grafis yang mempunyai peranan penting. Karena jika, tidak adanya kesatuan dalam sebuah karya desain akan membuat karya terlihat berantakan dan mengakibatkan sebuah karya tidak nyaman dipandang. Maka dari itu, para desainer grafis harus mengetahui cara untuk menyusun dan mengatur elemen-elemen desain ke dalam sebuah komposisi yang dapat memperlihatkan kesatuan di antara mereka secara visual (Landa, 2007), (4)Tipografi, Tipografi merupakan sebuah pembentukan atau pembuatan huruf melalui proses cetak (Rustan, 2010). Tipografi memiliki fungsi untuk membantu proses penyusunan dan pengaturan kata-kata ke dalam bentuk tulisan. sehingga konten atau pesan yang ingin disampaikan dapat dikomunikasikan dengan baik (Squire, 2006). Desainer perlu memahami berbagai macam visual dan elemen desain yang terdiri dari tipografi, serta memahami cara menggunakan dan menyusun tipografi dengan baik agar pesan yang terkandung dalam sebuah desain dapat dikomunikasikan dengan baik kepada audiensinya (Rustan, 2010), (5) Layout, Layout merupakan sebuah susunan atau letak berbagai macam elemen-elemen desain terhadap suatu bidang dalam media tertentu untuk mendukung konsep/ pesan dibawahnya yang diterapkan dalam bermacam-macam media. Layout berperan untuk memperjelas informasi serta konsep yang terdapat di dalam suatu bidang dan media (Rustan, 2009).

Penelitian ini dikuatkan oleh penelitian sebelumnya yang dilakukan oleh Abdul Malik (2017) menyatakan berdasarkan hasil penelitian menghasilkan program pemberdayaan dalam proses pengembangannya dilakukannya pelatihan pembuatan jam tangan dari kayu. Produksi dilakukan oleh warga belajar Kejar Paket B dan C setelah selesai pembelajaran kejar paket. Liunir (2016) juga menyatakan berdasarkan Pelaksanaan MKU telah mencapai tujuan yang telah ditetapkan yaitu : 1) meningkatkan pengetahuan, sikap dan keterampilan dalam bidang usaha busana bagi mahasiswa, 2) meningkatkan kemampuan manajerial , berkomunikasi dan bersosialisasi dengan karyawan dan pihak industri. Rina Murfiana (2016) juga berpendapat berdasarkan Hasil penelitian yang dilakukan menunjukkan bahwa alumni SMK Negeri 1 Calang khususnya Jurusan Tata Busana telah mengembangkan usaha menjahit busana, dalam bentuk usaha atelier dan modiste. Alumni SMK Negeri 1 Calang ini termotivasi mengembangkan usaha untuk mengaplikasikan ilmu yang telah dimiliki dan membantu perekonomian keluarga

\section{Metode}

\section{Jenis dan Kegiatan Magang}

Sebelum memulai kegiatan magang, Mahasiswa mendapat Workshop ICE. Workshop ini bertujuan memberi pengarahan kepada peserta magang sebelum ditempatkan di tempat magang. Pengarahan yang diberikan meliputi jadwal kerja, penempatan bagian dan pembimbingan mahasiswa dan menekankan kepada mahasiswa magang khususnya untuk bersikap disiplin baik dalam hal waktu maupun dalam melakukan segala tugas yang diberikan atasan maupun pegawai yang ada di bagiannya masing-masing.

Pelaksanaan magang di kantor "Bintang 5 Production" yang dilaksanakan selama 5 Minggu. Pelaksaan Magang dimulai pada tanggal 8 April 2018 Sampai dengan Tanggal 11 Mei 2018. Jam kerja pada hari Senin sampai Jumat mulai pukul 09.30 WIB sampai dengan pukul 12.30 WIB. Selama proses kegiatan magang Mahasiswa ditempatkan pada bagian Design dan EO. Jadwal Jam Kerja di Kantor Dinas Sosial dan Tenaga Kerja Surabaya: (a) Senin - Jumat, (b) Jam Masuk mulai pukul 09.30 WIB sampai dengan 12.30 WIB

\section{Prosedur Magang}

Berdasarkan pada jadwal pelaksanaan kegiatan magang yang telah disepakati oleh CV. Bintang Lima Mahardikka dan Universitas PGRI Madiun maka mahasiswa diberi tanggung jawab pada bagian Design dan EO selama 33 hari, untuk itu mahasiswa harus dapat beradaptasi dengan lingkungan kerja di bagian tersebut. Peraturan yang harus dipatuhi oleh peserta magang sebagai berikut: (a) Hadir setiap hari Senin - Jumat pada pukul 09.30 WIB, (b) Istirahat pukul 12.00 WIB - 13.30 WIB, (c) Jika ada kepentingan dan harus meninggalkan kantor harus meminta izin terlebih dahulu kepada yang bersangkutan, (d) Berpakaian Sopan dan rapi, celana panjang dan atasan berkerah 


\section{Hasil dan pembahasan}

\section{Manajemen CV. Bintang Lima Mahardikka}

CV. Bintang Lima Mahardika atau lebih dikenal dengan Bintang 5 Production merupakan sebuah perusahaanEvent Organizer (EO) \& Event Supplier dan Digital Printing \& Advertising yang berlokasi di Jalan Pringgodani No.1 Madiun. Ruang lingkup kerja Bintang 5 Production memayungi dua perusahaan, SatuAtap dan A1 Media mencakup penyelenggaraan acara (Event Organizer), persewaan alat-alat event, termasuk Sound system, Lighting, dan tenda. Selain itu juga terdapat jasa percetakan dan periklanan berupa baliho yang dikelola oleh A1 Media.Gedung Bintang 5 Production terdiri dari dua lantai. Lantai dasar terdiri dari front office, ruang desain dan ruang produksi untuk percetakan banner. Sedangkan lantai 2 merupakan kantor untuk SatuAtap serta ruang pertemuan.

\section{Jam kerja}

Jam kerja normal untuk pegawai jam 8.00 - 17.00 setiap hari Senin sampai Sabtu. Untuk hari minggu dan hari libur nasional, Bintang 5 Production tidak beroperasi. Sedangkan jam kerja bagi mahasiswa magang di antara jam kerja normal dengan durasi minimal 3 jam setiap hari Senin sampai Jumat. Apabila ada event atau kekurangan tenaga kerja, mahasiswa magang ambil bagian dalam setiap kegiatan yang sekiranya membutuhkan.

\section{Lingkup Kerja}

Lingkup kerja utama bagi mahasiswa magang adalah bagian desain digital.Software utama yang digunakan untuk desain adalah CorelDRAW, akan juga memungkinkan untuk dikerjakan menggunakan aplikasi lain seperti Adobe Photoshop dan Adobe Illustrator. Untuk proses desain terdiri dari beberapa tahapan: (1) Menerima konsep dasar dari pelanggan, (2) Proses desain dengan supervisi langsung dari pelanggan (jika di tempat), (3) Konfirmasi hasil desain dikirim ke kontak pelanggan menunggu persetujuan atau revisi, (4) Hasil desain dicetak atau hanya dalam bentuk soft file. Apabila pekerjaan di bagian tim desain bisa diatasi, mahasiswa pindah ke divisi lain yaitu administrasi dan Front Office.

Selama kegiatan magang berlangsung, mahasiswa dibimbing langsung oleh tim desain mengenai permintaan konsumen dalam pembuatan desain,teknik pengoperasian aplikasi desain, CorelDRAW, serta pengerjaan beberapa desain yang diminta oleh klien.Mahasiswa diberi instruksi yang sangat jelas dan mudah dipahami setiap kali ada kendala dalam pengerjaan suatu desain.

\section{Teknologi dan Fasilitas Kerja}

Bintang 5 Production memiliki fasilitas yang cukup lengkap dalam pengerjaan proyek. Fasilitas peralatan kerja diantaranya: (1) Ruang kerja standar dengan AC, (2) Jaringan internet yang cepat, (3) Komputer dengan spesifikasi tinggi yang terinstal berbagai macam software desain termasuk CorelDRAW, Adobe Master Series serta aplikasi lainnya (Tabel1).

Tabel 1. Teknologi berupa Software yang terinstal pada komputer di Bintang 5 Production.

\begin{tabular}{lllll}
\hline No & \multicolumn{1}{c}{ Software } & \multicolumn{2}{c}{ Kegunaan } \\
\hline 1 & CorelDRAW X5 & Untuk desain grafis berbasis vektor & \\
2 & Adobe Photoshop CS4 & Desain grafis berbasis pixel & \\
3 & Ms. Office 2007 & $\begin{array}{l}\text { Presentasi pada klien dan pengelolaan dokumen } \\
\text { administrasi }\end{array}$ & Desain 3D untuk presentasi pada klien & \\
4 & Google Sketchup 2018 & Sun & \\
\hline
\end{tabular}

Tabel 2. Fasilitas yang digunakan dalam pengerjaan proyek Perusahaan

Sumber: Bintang 5 Production

\begin{tabular}{lll} 
No. & \multicolumn{1}{c}{ Fasilitas } & \multicolumn{1}{c}{ Kegunaan } \\
\hline 1 & PC, komputer & Pengerjaan desain grafis, 3D dan administrasi \\
2 & Percetakan banner & Mencetak produk kerja berupa banner dengan lebar sampai 6 meter \\
3 & Printer & $\begin{array}{l}\text { Mencetak produk kerjakedalam kertas ukuran A4 atau lebih kecil. } \\
\text { Bertukar file antar komputer tanpa menggunakan alat eksternal seperti } \\
\text { flasdisk }\end{array}$ \\
& Sharing Network & $\begin{array}{l}\text { Penghubung computer ke jaringan internet sekaligus antar komputer } \\
\text { untuk memudahkan perpindahan file. }\end{array}$ \\
5 & WIFI & Untuk rapat intern Bintang 5 Production \\
6 & LCD Proyektor & Berkomunikasi dengan klien, memudahkan dalam komunikasi \\
\hline
\end{tabular}




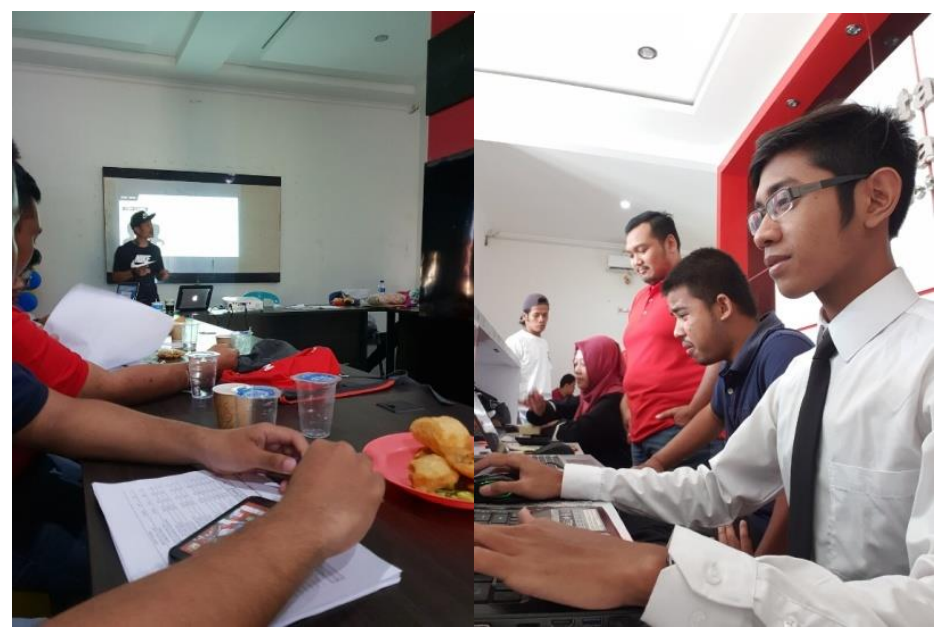

(Meeting BluderCokro Fest 2018) （Customer Service dan sorting data)

Gambar 1. Dokumentasi kegiatan selama magang

\section{Simpulan dan saran}

Banyak hal yang dipelajari oleh mahasiswa selama proses magang di CV. Bintang Lima Mahardikka, mulai dari lingkup desain yang menjadi target utama mahasiswa untuk dipelajari, manajemen sebuah tim dalam suatu event, serta komunikasi dengan klien selama di bagian front office. Pembimbing lapangan dan staf yang ramah dalam memberikan instruksi ataupun saran menimbulkan rasa keinginan untuk belajar lebih dalam mengenai manajemen suatu perusahaan yang bergerak dalam dunia desain berkonsep. Selain itu, kesempatan yang diberikan kepada mahasiswa untuk menjadi bagian dalam tim pengadaan event di dua kegiatan (Bluder Cokro Fest 2018 dan Madiun Motor Fest 2018) menjadi pengalaman luar biasa dan sekaligus menjadi pelajaran berharga mengenai komunikasi sebuah tim kerja. Meskipun terkendala dengan berbagai hal selama magang berlangsung, semua dapat teratasi dengan kerja sama tim yang baik antara mahasiswa magang dengan staf perusahaan yang bersangkutan.

Setelah melaksanakan kegiatan magang selama satu bulan di CV. Bintang Lima Mahardikka, mahasiswa mempunyai saran untuk Universitas PGRI Madiun dan CV. Bintang Lima Mahardikkas untuk terus menjalin kerja sama yang kemungkinan ke depannya apabila ada program kampus yang serupa dengan Program Pengembangan Kewirausahaan (PPK) dan membutuhkan mitra, maka CV. Bintang Lima Mahardikka bisa menjadi salah satu pilihan untuk bidang teknologi. Sedangkan saran untuk pihak manajemen CV. Bintang Lima Mahardikka untuk memberikan tugas bagi peserta magang yang memiliki waktu luang ketika di lingkungan kerja.

\section{Daftar Rujukan}

Abdul Malik, Sungkowo Edy Mulyono. 2017. Pengembangan Kewirausahaan Berbasis Potensi Lokal melalui Pemberdayaan Masyarakat. Journal of Nonformal Education and Community Empowerment. Volume 1 (1): 87-101, Juni.

Fakhruddin, Mulyono, S. E., Rifai, A., Utsman, \& Sutarto, J. (2012). Strategi pengembangan kewirausahaan masyarakat. Semarang: Widya Karya.

Frinces, Z.H., 2010, Pentingnya Profesi Wirausaha di Indonesia, Jurnal Ekonomi dan Pendidikan, Vol. 7, No. 1, April

Hafer, R.W., 2013, Entrepreneurship and State Economic Growth, Journal of Entrepreneurshop and Public Policy, Vol. 2, Issue 1, pp.67-79.

Helfand, J. (2016). Design: The Invention of Desire. New Haven: Yale University Press. 
Hermuningsih, S., Widiastuti, R. Kurniawan, V. R. B., 2017, Preferensi Selera Profil Usaha (Business Profile Appetite) pada Program Kewirausahaan Mahasiswa (Studi Kasus pada Mahasiswa di Universitas Sarjanawiyata Tamansiswa Yogyakarta), Prosiding Seminar Kewirausahaan, Universitas Indraprastha PGRI, Jakarta.

Landa, R. (2011). Take a Line for a Walk: A Creativity Journal. Wadsworth: Wadsworth.

Landa, R., Gonnella, R., \& Brower, S. (2007). 2d: Visual Basics for Designers. Kentucky: Delmar Learning.

Liunir. 2016. Magang Kewirausahaan Sebagai Upaya Peningkatan Manajerial Bisnis Mahasiswa. Jurnal Ekonomi dan Bisnis. Vol 3 No 1.

Rina Murfiana, Fikriah Noer, Rosmala Dewi. 2016. Pengembangan Kewirausahaan Di Kalangan Alumni SMK Negeri 1 Calang. Jurnal Ilmiah Mahasiswa Pendidikan Kesejahteraan Keluarga Vol: 1 No: 1 edisi Juli.

Rustan, S. (2009). Mendesain Logo. Jakarta: PT Gramedia Pustaka Utama.

Rustan, S. (2010). Font And Tipografi . Gramedia Pustaka Utama.

Squire, V., Forssman, F., \& Willberg, H. P. (2006). Getting it Right with Type: The Dos and Don'ts of Typography. London: Laurence King Publishing. 